ARTICLE

DOI: $10.1038 / s 41467-018-04161-4$

\title{
Supramolecular latching system based on ultrastable synthetic binding pairs as versatile tools for protein imaging
}

Kyung Lock Kim (1) ${ }^{1}$, Gihyun Sung ${ }^{2}$, Jaehwan $\operatorname{Sim}^{3}$, James Murray ${ }^{1}$, Meng Li ${ }^{1}$, Ara Lee ${ }^{2}$, Annadka Shrinidhi', Kyeng Min Park (1) ${ }^{1,4}$ \& Kimoon Kim (1) 1,2,3,5

Here we report ultrastable synthetic binding pairs between cucurbit[7]uril (CB[7]) and adamantyl- (AdA) or ferrocenyl-ammonium ( $F C A$ ) as a supramolecular latching system for protein imaging, overcoming the limitations of protein-based binding pairs. Cyanine 3conjugated $\mathrm{CB}[7]$ ( $\mathrm{Cy} 3-\mathrm{CB}[7]$ ) can visualize AdA- or FcA-labeled proteins to provide clear fluorescence images for accurate and precise analysis of proteins. Furthermore, controllability of the system is demonstrated by treating with a stronger competitor guest. At low temperature, this allows us to selectively detach $\mathrm{Cy} 3-\mathrm{CB}[7]$ from guest-labeled proteins on the cell surface, while leaving $\mathrm{Cy} 3-\mathrm{CB}[7]$ latched to the cytosolic proteins for spatially conditional visualization of target proteins. This work represents a non-protein-based bioimaging tool which has inherent advantages over the widely used protein-based techniques, thereby demonstrating the great potential of this synthetic system.

\footnotetext{
${ }^{1}$ Center for Self-assembly and Complexity (CSC), Institute for Basic Science (IBS), Pohang 37673, Republic of Korea. ${ }^{2}$ Division of Advanced Materials Science, Pohang University of Science and Technology (POSTECH), Pohang 37673, Republic of Korea. ${ }^{3}$ School of Interdisciplinary Bioscience and Bioengineering, Pohang University of Science and Technology (POSTECH), Pohang 37673, Republic of Korea. ${ }^{4}$ Department of Nanomaterials and Engineering, University of Science and Technology (UST), Daejeon 34113, Republic of Korea. ${ }^{5}$ Department of Chemistry, Pohang University of Science and Technology (POSTECH), Pohang 37673, Republic of Korea. These authors contributed equally: Kyung Lock Kim, Gihyun Sung. Correspondence and requests for materials should be addressed to K.M.P. (email: kmpark@ibs.re.kr) or to K.K. (email: kkim@postech.ac.kr)
} 
T he streptavidin-biotin (SA-BT) pair is a naturally occurring protein-ligand binding pair with high binding affinity $\left(K \sim 10^{13} \mathrm{M}^{-1}\right)$ in physiological conditions ${ }^{1}$. The high binding affinity has allowed SA-BT to be used as a non-covalent tool for a wide variety of bioapplications such as immobilization and purification of biomolecules, biosensing, and bioimaging ${ }^{2-4}$. Nevertheless, since SA-BT is a natural protein-based binding pair, it has unavoidable limitations-especially in a cellular environment such as being susceptible to enzymatic degredation ${ }^{5}$. In addition, its large size $(52 \mathrm{kDa})$ hampers precise and accurate molecular-level imaging ${ }^{6}$, cell permeability and the strong interaction between SA and BT is practically irreversible, unless SA is denatured using harsh conditions, which are undesirable for protein analysis, especially for imaging. Furthermore, endogenous BT blocks the binding sites of $\mathrm{SA}^{7,8}$ and endogenously biotinylated proteins may generate false positives ${ }^{9-11}$. Additional treatments with commercial kits with skillful handling can help reduce the interference from endogenously biotinylated species. However, unaddressable issues remain in the use of the natural binding pair system for cellular bio-imaging. Therefore, a small molecule-based artificial binding pair system with ultrahigh binding affinity is urgently required.

Cucurbit $[n]$ urils $(\mathrm{CB}[n], n=5-8,10$, and 14$)$, a family of pumpkin-shaped synthetic host molecules, have unique molecular recognition properties ${ }^{12,13}$. Especially, CB[7] forms ultrastable and highly specific host-guest complexes with its guests such as ferrocenemethyl- (FcA), adamantyl- (AdA), and diamantyl ammonium derivatives. The binding affinities $(K$ $\left.10^{12}-10^{17} \mathrm{M}^{-1}\right)^{14-21}$ are remarkably high, and comparable to or even higher than that of SA-BT. The strong binding of $\mathrm{CB}[7]$ with its guest, which is easily and selectively attached, is reminiscent of a mechanical latch ${ }^{22}$. The CB[7]-based ultrastable binding pairs have been utilized for various applications such as biosensors $^{23}$, under-water adhesives ${ }^{24}$, protein fishing ${ }^{25}$, guestregulated catalysis ${ }^{26}$, guest-responsive activation of therapeutic effects $^{27}$, and single vesicle contents mixing assays ${ }^{28}$. However, the ultrastable host-guest interaction between $\mathrm{CB}[7]$ and $\mathrm{AdA}$ (or other tight binders) has not been exploited for cellular imaging, despite its own unique features that make it useful for cell biology including: (1) a stable chemical structure that is robust in a cellular environment and not affected by enzymatic degradation; (2) their bio-orthogonality in binding to biomolecules; (3) their small size compared to other protein-based binding pairs such as SA-BT enabling for efficient cellular uptake; (4) controllable binding affinity by treatment with competing guests allowing for selective dissociation of the host-guest assembly, on demand; and (5) scalability using known chemical synthetic methods for costeffective and convenient uses. Recently, Urbach and Isaacs reported the synthesis of tetramethylrhodamine-conjugated $\mathrm{CB}$ [7] (dye-CB[7]) and its intracellular uptake into cells ${ }^{29}$. We have also reported the synthesis and use of a dye-CB[7], namely cyanine 3-conjugated $\mathrm{CB}[7]$ ( $\mathrm{Cy} 3-\mathrm{CB}[7])$ for in vitro imaging purposes ${ }^{28,30}$. Although both of them showed the great potential of $\mathrm{CB}[7]$-dye conjugates as imaging probes, their ability to form ultrastable and controllable host-guest interactions has not been exploited for imaging of cellular biomolecules, structures, or processes.

Herein, we report the versatile use of $\mathrm{Cy} 3-\mathrm{CB}[7]$-guest pairs as a bioimaging tool that can be used to specifically visualize proteins on the surfaces of cells and animals and in specific cellular compartments. We achieved this by employing a variety of different conjugation techniques to label cellular proteins of interest with AdA (or FcA) which then serve to localize Cy3-CB[7] at the cellular region of interest. In addition, using the reversible binding between $\mathrm{Cy} 3-\mathrm{CB}[7]$ and $\mathrm{FcA}$ (or AdA) labeled proteins, by treatment with a strong competing guest, the proteins that were internalized into cells were selectively visualized, by unlatching the Cy3-CB[7] from the cell surface proteins. (Fig. 1). This work represents the first example of a non-protein-based bioimaging platform which gives it inherent advantages over currently and widely used protein-based methods, such as resistance to proteases, a bioorthogonal binding mechanism, a small a

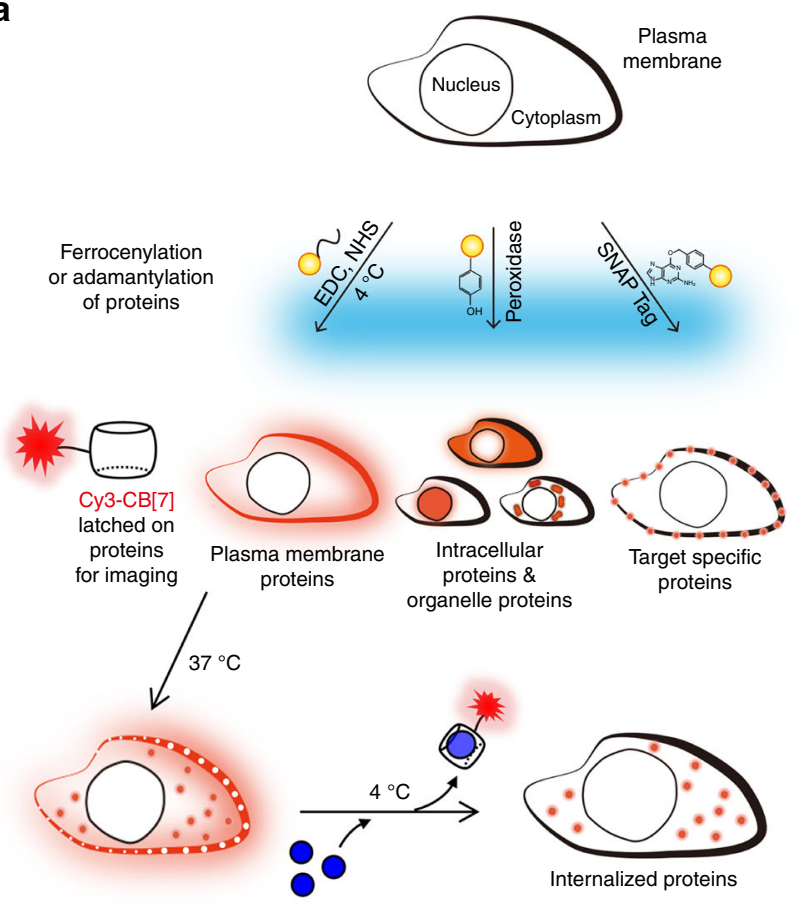

b Supramolecular switchable latching for protein imaging
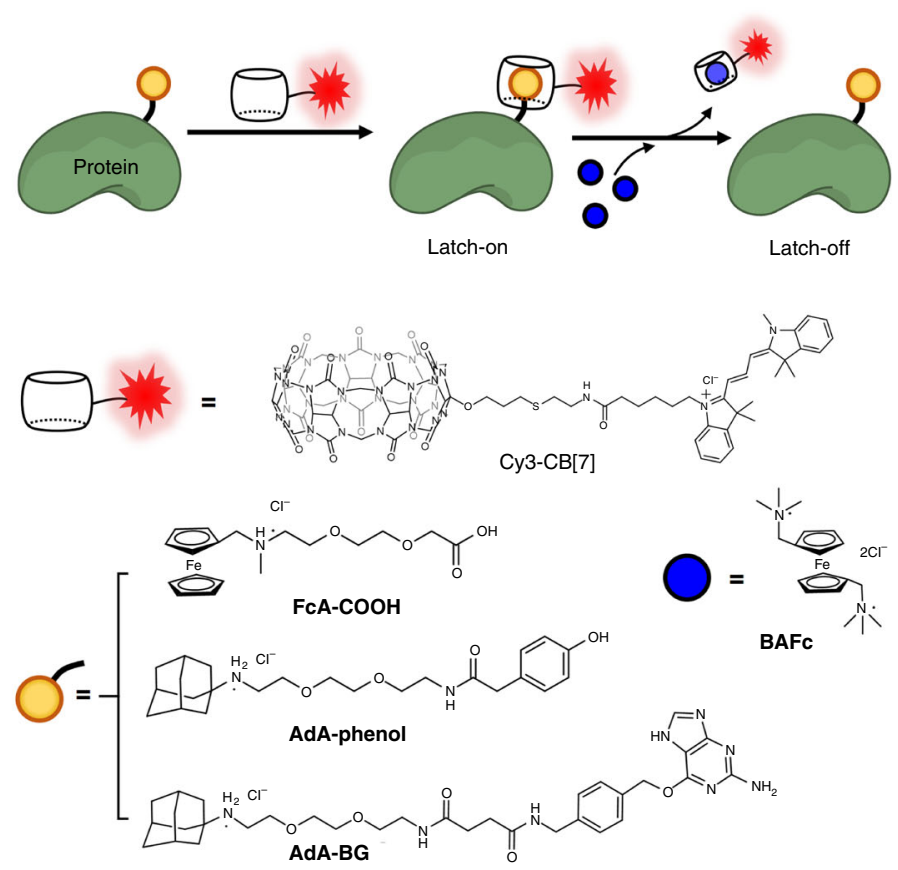

Fig. 1 Schematic illustration of protein imaging. a Universal and selective imaging of cellular proteins using a switchable supramolecular latching system based on the ultrastable host-guest interactions between $\mathrm{Cy3}-\mathrm{CB}[7]$ and $\mathrm{AdA}$ (or FcA); b CB[7]-based ultrastable binding pairs used in this study 


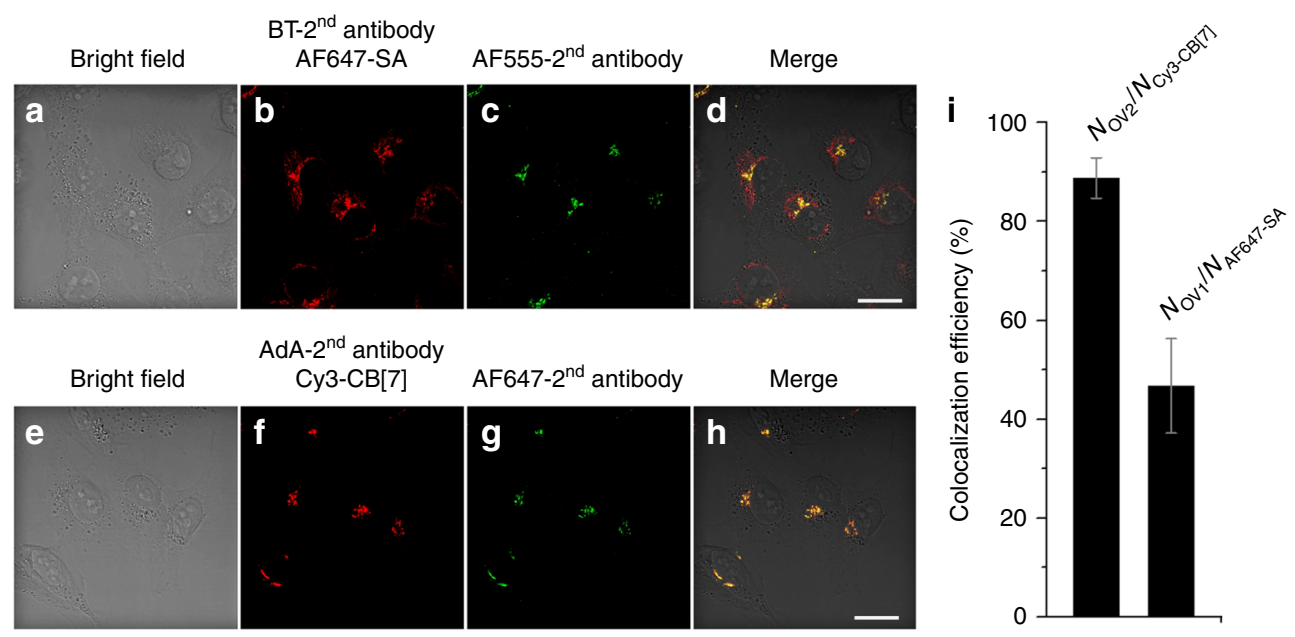

Fig. 2 Visualization of Golgi using SA-BT and CB[7]-AdA. Confocal laser scanning microscopy images of Golgin97 monoclonal antibody treated MCF-7 cells a-d after treatment of BT-labeled secondary antibody with AF647-SA and AF555-secondary antibody, and e-h after treatment of AdA-labeled secondary antibody with Cy3-CB[7] and AF647-secondary antibody, scale bar $=20 \mu \mathrm{m}$. i A bar graph of colocalization efficiency of fluorescence signals between AF647-SA and AF555-secondary antibody, and Cy3-CB[7] and AF647-secondary antibody. The bar represents mean \pm s.d. (see Methods for calculation of the colocalization efficiency and Supplementary Figure 5 for magnification of cells in Fig. 2.)

size and, easily controllable binding affinity. The aforementioned merits of the $\mathrm{CB}[7]$-guest pairs are retained in cellular conditions; the most important of these being that the high-affinity host-guest binding is retained, which enables a 'supramolecular latch-on' between the labeled proteins and $\mathrm{Cy} 3-\mathrm{CB}[7]$. Interestingly, the host-guest complex can be dissociated (the latch-off state) by guest exchange with a strong competitor, such as $1,1^{\prime}$-bis (trimethylammoniomethyl)ferrocene (BAFc), thereby providing selective conditional visualization of target proteins. Considering the synthetic nature, their bioorthogonality in binding and conditionally switchable visualization of cellular proteins of interest, we believe that the $\mathrm{Cy} 3-\mathrm{CB}[7]$-guest pairs represent a general, non-protein-based and efficient cellular bioimaging tool for almost any target proteins which are labeled with AdA (or FcA).

\section{Results}

Ultrastable synthetic binding pair as a protein imaging tool. To demonstrate the versatility of our approach, we targeted several proteins in a variety of different locations, namely the plasma membrane, various intracellular compartments (the cytoplasm, nucleus, and mitochondria), and finally the surface of a live animal, Caenorhabditis elegans. Prior to imaging with $\mathrm{Cy} 3-\mathrm{CB}[7]$, using the concept of supramolecular latching, the proteins of interest were targeted by labeling with AdA (or FcA), a process we term adamantylation (or ferrocenylation), using various chemical and biological approaches as follows: (1) ferrocenylation of plasma membrane proteins using EDC (1-ethyl-3-(3-dimethylaminopropyl)-carbodiimide hydrochloride) coupling; (2) adamantylation of proteins in specific organelles using proximitydependent enzyme-assisted labeling using horseradish peroxidases (HRPs) and an engineered ascorbate peroxidase (APEX); and (3) adamantylation of specific target proteins through the use of a self-labeling proteins tag, namely SNAP-tag ${ }^{\circledR}$ (SNAP-tag) which can be expressed as a fusion with the target protein. To demonstrate the extra control that our system provides, conditional visualization of proteins was performed by exploiting the controllable binding of the host-guest complex. Cells were treated with a strong competing guest $(\mathrm{BAFc})$ at a low temperature $\left(4^{\circ}\right.$ $\mathrm{C}$ ), at which BAFc does not internalize, so only the $\mathrm{Cy} 3-\mathrm{CB}[7]$ on the cell surface was removed since it forms a more stable complex with $\mathrm{BAFc}$ (taking the supramolecular latch-off), while keeping $\mathrm{Cy} 3-\mathrm{CB}[7]$ inside the cells latched to the proteins.

We first compared the imaging ability of $\mathrm{Cy} 3-\mathrm{CB}[7]$ to that of Alexa Fluor (AF) 647 (AF647)-SA to validate the ultrastable binding pairs as a protein imaging tool. As a test system, we decided to image an organelle, namely the Golgi. We used a Golgi-specific primary antibody (Golgin97 monoclonal antibody, CDF4) which selectively interacts with a trans-Golgi network protein, Golgin 97 . The primary antibody was recognized by AdA or BT-conjugated secondary antibody (see Supplementary Information for synthesis), which was later visualized by treating with Cy3-CB[7] or AF647-SA, respectively, under a confocal laser scanning microscope (Fig. 2). For a direct comparison of imaging ability for target proteins in the cells, AF647- and AF555conjugated secondary antibodies were co-administered alongside Cy3-CB[7] and AF647-SA, respectively. The cells treated with the BT-secondary antibody showed more spread-out fluorescence signals from AF647-SA than that of the AF555-secondray antibody (Fig. 2d, Supplementary Figure 5A and C). This result indicated that AF647-SA visualized not only target proteins in Golgi but also off-target proteins in cytosol. This observation of unintended fluorescence signals over the whole cytoplasm, even after extensive washing, confirmed that the cells contained a nonignorable amount of endogenously biotinylated proteins. However, in the case of the cells treated with AdA-secondary antibody, the fluorescence signals of Cy3-CB[7] was well-merged with that of AF647-secondray antibody (Fig. 2h, Supplementary Figure 5B and D), in contrast to that of AF647-SA with AF555-secondary antibody. We calculated the colocalization efficiency (Fig. 2i) of the fluorescence signals from AF647-SA and AF555-secondary antibody $(49 \pm 10 \%)$, and $\mathrm{Cy} 3-\mathrm{CB}[7]$ and AF647-secondray antibody $(89 \pm 4 \%)$ (see Methods for calculation); this quantitative analysis strongly suggested that the synthetic host-guest pair system provides more accurate and precise imaging of target proteins.

Visualization of FcA-labeled plasma membrane proteins. Since many dynamic cellular processes occur at the cell membrane, such as clustering and endocytosis, visualization of plasma membrane proteins is important. We have already demonstrated 


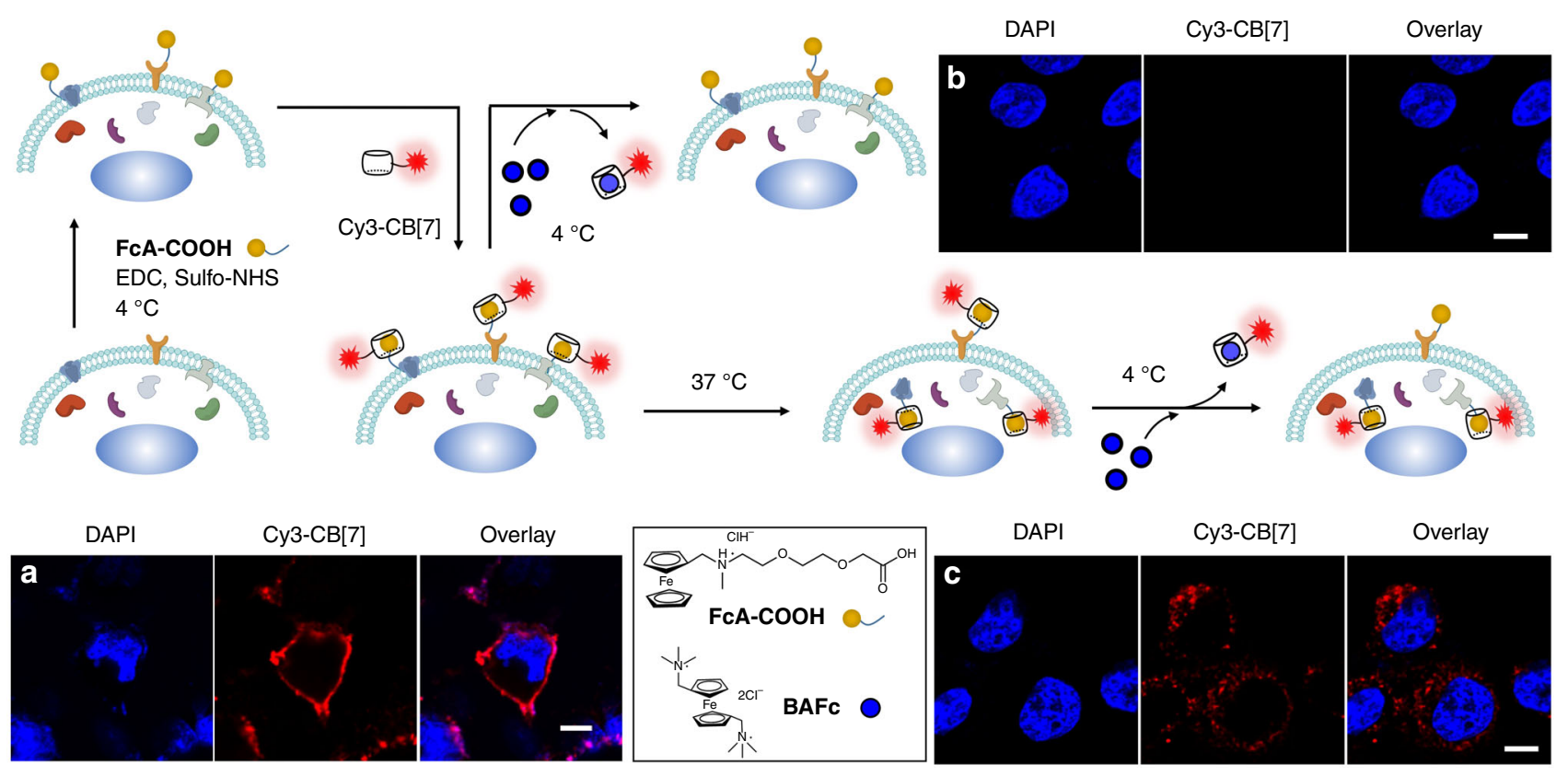

Fig. 3 Selective visualization of intracellularly translocated proteins. Schematic illustration of the ferrocenylation of plasma membrane proteins and

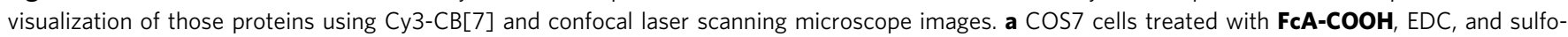
$\mathrm{NHS}$ at $4{ }^{\circ} \mathrm{C}$ for $30 \mathrm{~min}, \mathbf{b}$ the cells further incubated with BAFc at $4{ }^{\circ} \mathrm{C}$ for 20 min after a, and $\mathbf{c}$ the cells treated with BAFc at $4{ }^{\circ} \mathrm{C}$ for 20 min after additional incubation for $1 \mathrm{~h}$ at $37^{\circ} \mathrm{C}$ of the cells in $\mathbf{a}$. Scale bar $=10 \mu \mathrm{m}$

that plasma membrane proteins can be selectively ferrocenylated with FcA-COOH through EDC coupling at $4{ }^{\circ} \mathrm{C}$ at which intracellular uptake of FcA-COOH was significantly reduced ${ }^{25}$. To test whether proteins on plasma membranes are selectively visualized using the $\mathrm{CB}$ [7]-based ultrastable binding pair, live COS7 cells were treated with $\mathbf{F c A - C O O H}$ as previously reported ${ }^{25}$, then the cells were treated with Cy3-CB[7] (100 nM). Confocal laser scanning microscopy revealed that the signals from Cy3-CB[7] were mostly observed at the periphery of the cells (Fig. 3a), which indicated the successful supramolecular latching of $\mathrm{Cy} 3-\mathrm{CB}[7]$ to the ferrocenylated proteins on the plasma membrane. Hardly any fluorescence signals (Supplementary Figure 6) were observed without FcA-COOH treatment, suggesting that the ultrastable host-guest interaction between $\mathrm{Cy} 3-\mathrm{CB}[7]$ and $\mathbf{F c A}$ moiety is crucial for the imaging of live cells, and that Cy3-CB[7] (100 nM) rarely adsorb non-specifically to the surface of the live cells.

Selective visualization of proteins translocated into cytosol. Visualization of the translocation of plasma membrane proteins, such as epidermal growth factor receptor (EGFR) and G-protein coupled receptor (GPCR), in cells is necessary to understand their role in complex and dynamic processes such as endocytosis. By controlling the binding affinity of the host-guest complex, we selectively visualized membrane proteins that had been translocated into the cytosol. This was achieved by selectively unlatching Cy3-CB[7] from FcA-labeled proteins on the cell surface, while Cy3-CB[7]-latched proteins inside the cells were left untouched. The cells were treated with BAFc $(100 \mu \mathrm{M})$, at $4{ }^{\circ} \mathrm{C}$, which has approximately 3 orders higher binding affinity to $\mathrm{CB}[7]$ compared to that of FcA moiety ${ }^{14-16}$, which causes $\mathrm{Cy} 3-\mathrm{CB}$ [7] to unlatch from the FcA. The treatment almost completely abolished the fluorescence signal from $\mathrm{Cy} 3-\mathrm{CB}$ [7] (Fig. 3b) suggesting that Cy3-CB[7] was unlatched from the FcA-labeled proteins on the cell surface. After demonstrating the unlatching of $\mathrm{Cy} 3-\mathrm{CB}[7]$ from the cell surface proteins, we proceeded to selectively visualize translocated proteins. Another sample of cells labeled with $\mathrm{Cy} 3-\mathrm{CB}$ [7] was further incubated at $37^{\circ} \mathrm{C}$ for $1 \mathrm{~h}$ to promote translocation of proteins, as a part of the normal metabolism of living cells. After treatment with BAFc at $4{ }^{\circ} \mathrm{C}$, the fluorescence signal of Cy3-CB[7] was only visible inside the cells (Fig. 3c). These results indicated that we were observing the translocation of Cy3-CB[7] anchored plasma membrane proteins into the cells. In addition, the cells exhibited no significant morphological changes during the course of the experiment suggesting that the supramolecular latching system is not severely cytotoxic. Taken together, the conditional supramolecular unlatching of $\mathrm{Cy} 3-\mathrm{CB}$ [7] from the FcA labeled proteins on living cells, by guest exchange with a strong competitor (BAFc), allowed us to visualize, selectively, the proteins that underwent intracellular translocation.

Visualization of intracellular proteins. Visualization of intracellular proteins is also important since most proteins are found within the cell. We used COS7 cells that were transfected (Lipofectamine $\mathrm{TM}^{\mathrm{TM}}$ 2000) with plasmid DNA for the expression of FLAG $^{\oplus}$-tagged enhanced green fluorescent protein (FLAG-eGFP) in the cytoplasm. FLAG is a polypeptide protein tag (DYKDDDDK) which can be selectively recognized by a corresponding antibody (anti-FLAG primary antibody) ${ }^{31}$. After fixation of the cells with formaldehyde, the anti-FLAG primary antibody and a HRP-conjugated secondary antibody were sequentially treated to the cells for immunospecific introduction of HRP to the cytoplasmic FLAG-eGFP. When the fixed cells were treated with AdA-phenol (Supplementary Figure3) and $\mathrm{H}_{2} \mathrm{O}_{2}$, the HRP converted the phenol moiety of AdA-phenol to a phenyloxy radical, which then reacted with tyrosine residues on nearby proteins, thereby labeling the proteins with AdA (Fig. 4$)^{32}$. After quenching the remaining radicals with sodium azide and sodium ascorbate, the cells were treated with fluorescent dyes, namely $4^{\prime}, 6$-diamidine- $2^{\prime}$-phenylindole dihydrochloride (DAPI) and $\mathrm{Cy} 3-\mathrm{CB}[7]$ for fluorescence staining of each cell and the AdA-labeled proteins in the cells, respectively.

Fluorescence images (Fig. 4) showed the appearance of a green fluorescence signal spread over the whole cell which indicated 
that FLAG-eGFP was well expressed in the cytoplasm of the transfected cells. However, some of the cells that were stained with DAPI, showing blue fluorescence, did not emit the green fluorescence signal. This indicated that not every cell is transfected. Pleasingly, when the cells were treated with $\mathrm{Cy} 3-\mathrm{CB}$ [7], only the FLAG-eGFP expressed cells showed good overlap of the fluorescence signals from eGFP with that from Cy3-CB[7]. The non-transfected cells rarely showed any signal from $\mathrm{Cy} 3-\mathrm{CB}$ [7] since FLAG-eGFP was not present. This result suggested that adamantylation only took place in the presence of the HRPsecondary antibody, which, in turn, was only present where the primary anti-FLAG and eGFP were. As a control experiment, we also used cells that were expressing eGFP without a FLAG-tag, we observed negligible fluorescence signals from Cy3-CB[7] (Supplementary Figure 7), which indicated that no $\mathrm{Cy} 3-\mathrm{CB}[7]$ was present due to the absence of AdA in the cells. This result supports that the specific adamantylation in Fig. 4 was facilitated by the FLAG-tag-based immunospecifically anchored HRP-

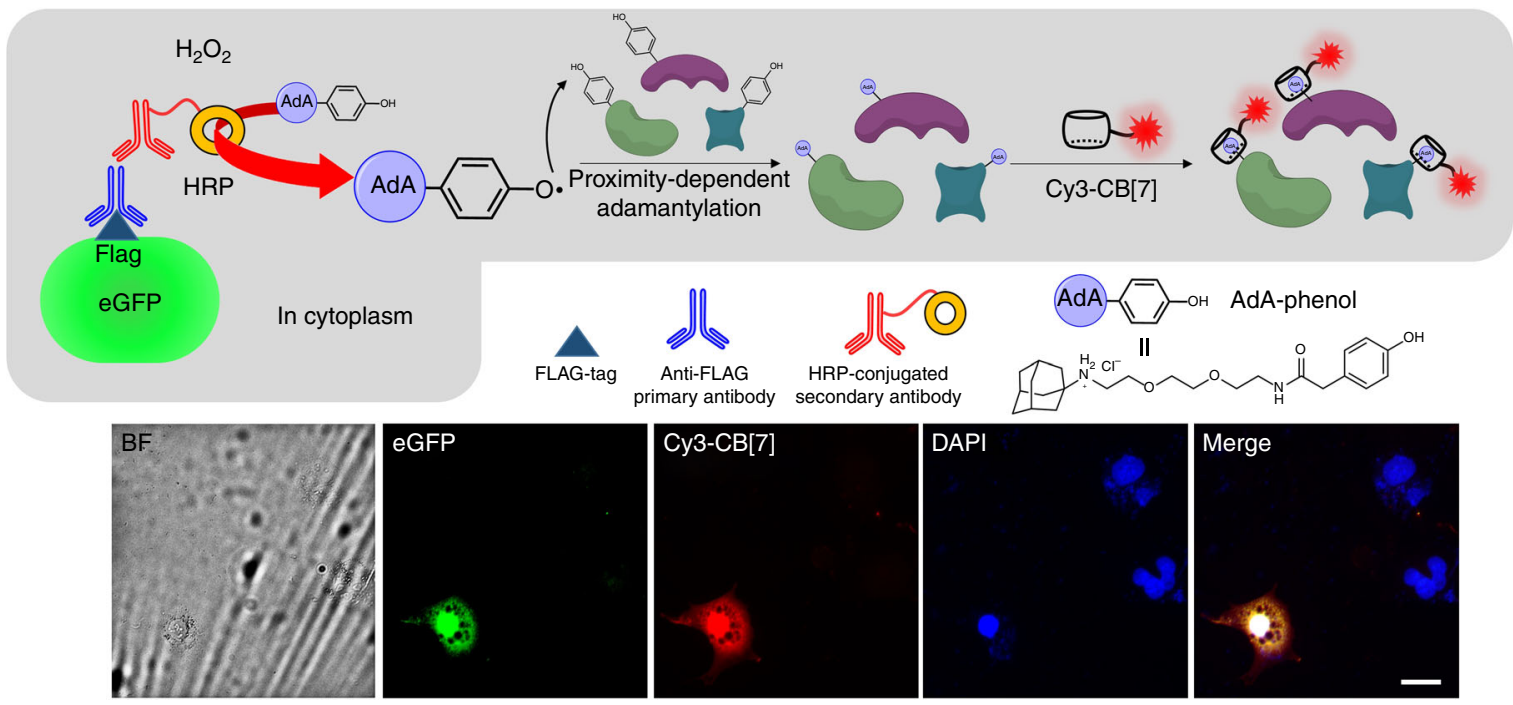

Fig. 4 Visualization of intracellular proteins. Schematic illustration for adamantylation on cytoplasmic proteins using immunospecifically introduced HRP on eGFP and fluorescence microscopy images of the fixed COS7 cells which have FLAG-eGFP expressed in cytoplasm. Scale bar $=20 \mu \mathrm{m}$

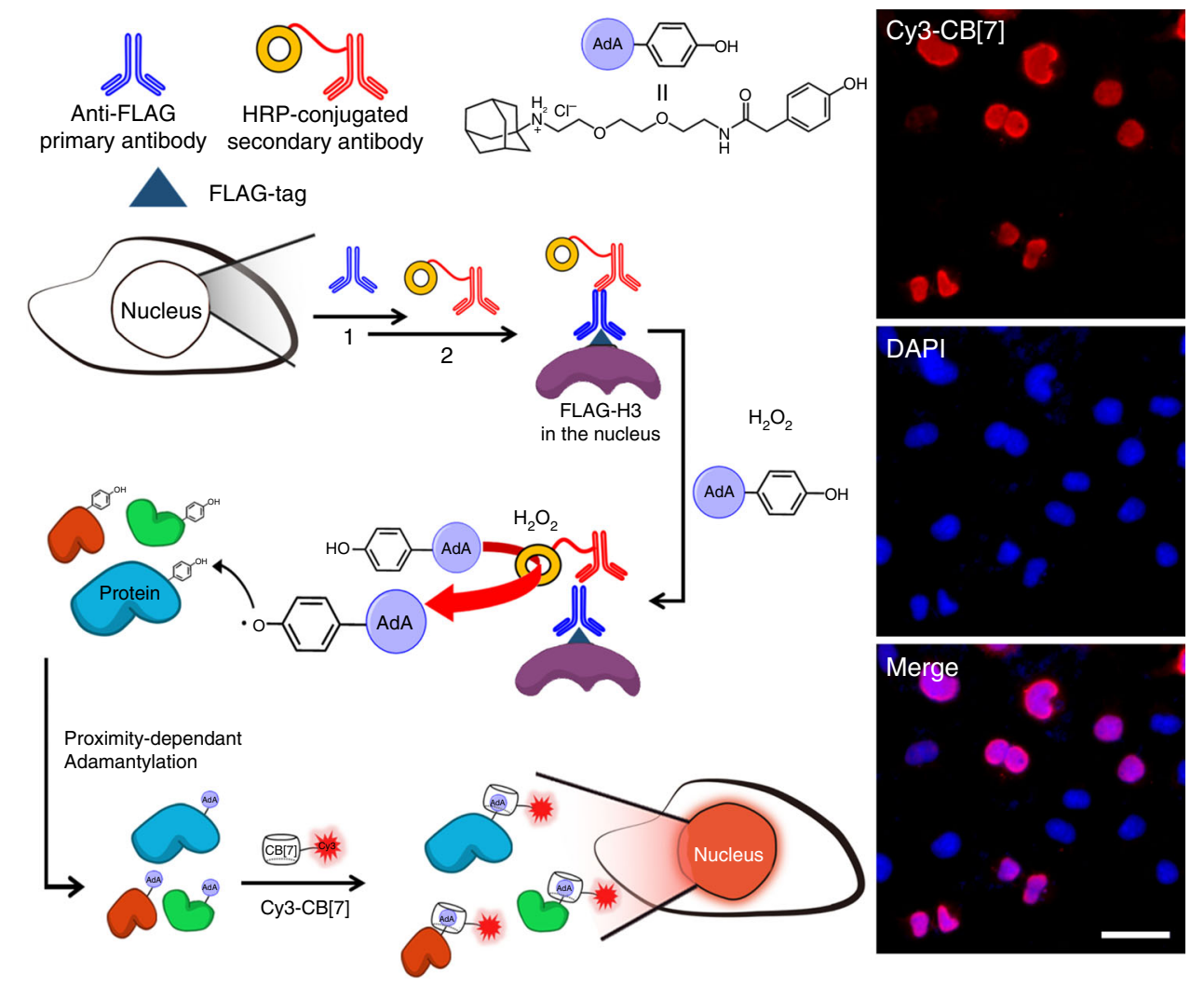

Fig. 5 Visualization of nuclear proteins. Schematic illustration for proximity-dependent adamantylation of nuclear proteins using immunoselectively introduced HRP on histone $\mathrm{H} 3$ and fluorescence microscopy images of the fixed COS7 cells which have FLAG-histone H3 expressed in the nucleus. Scale bar $=20 \mu \mathrm{m}$ 


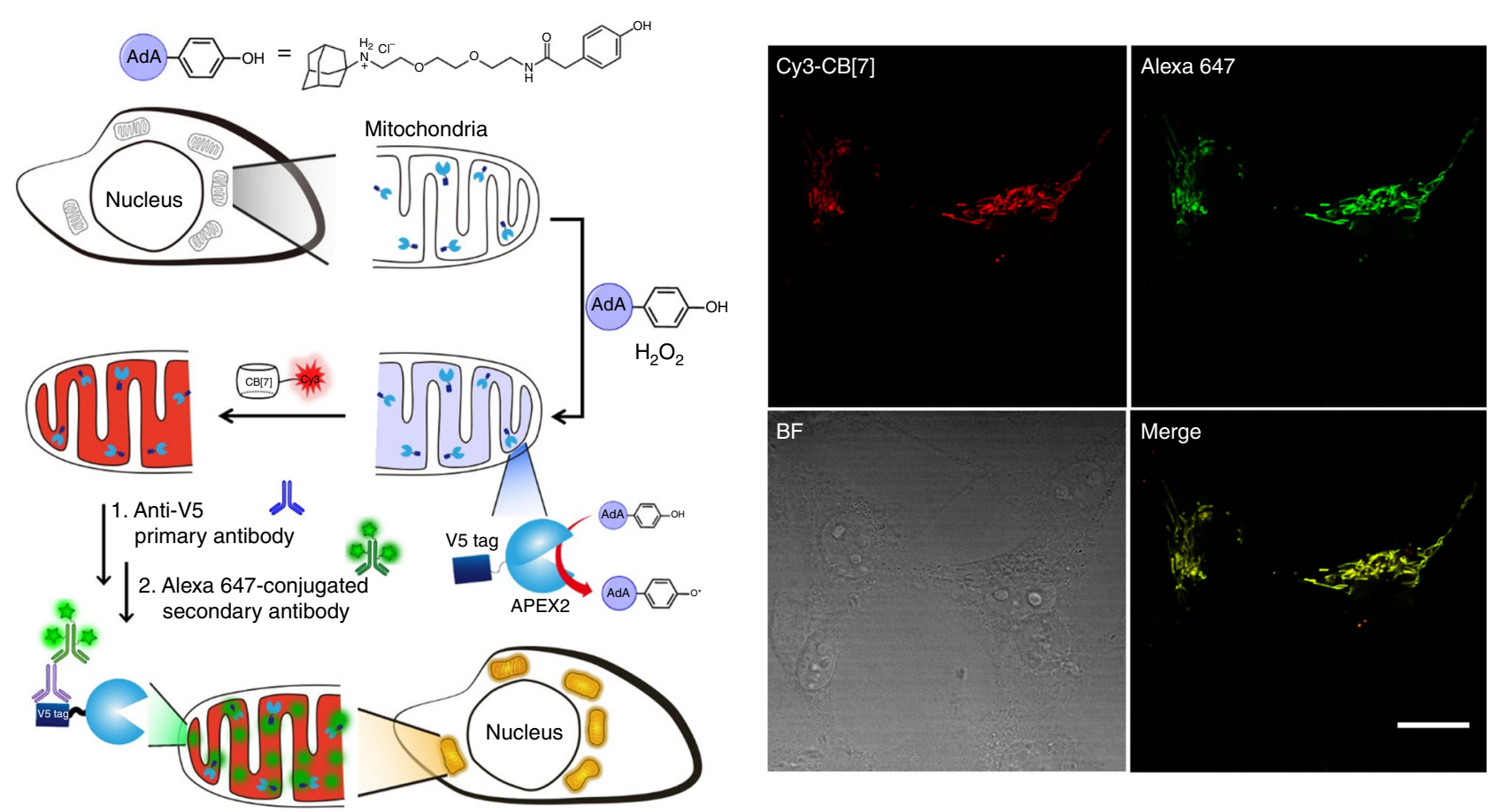

Fig. 6 Visualization of a subcellular organelle (mitochondria). Schematic illustration for proximity-dependent adamantylation to mitochondria proteins using mito-V5-APEX2 and immunofluorescence labeling of mito-V5-APEX2, and confocal laser scanning microscopy images of living COS7 cells which have mito-V5-APEX2 expressed in mitochondria. Scale bar $=20 \mu \mathrm{m}$

secondary antibody. In addition, the absence of a significant signal caused by non-specific interactions of $\mathrm{Cy} 3-\mathrm{CB}[7]$ in the fixed cells is encouraging for its potential use as a cellular imaging tool. Taken together, intracellular proteins can be labeled with AdA using immunospecifically anchored enzymes and the adamantylated proteins can be efficiently visualized with Cy3$\mathrm{CB}[7]$ using the highly selective and ultrastable host-guest interaction between $\mathrm{CB}[7]$ and $\mathrm{AdA}$, without interference by endogenous biomolecules.

Visualization of spatially resolved proteins. Cells are composed of diverse specialized subunits, namely organelles, each of which is usually compartmentalized by a lipid membrane to regulate intracellular trafficking of proteins and perform metabolic functions ${ }^{33}$. To understand the role of these subunits in cells, visualization of spatially restricted proteins in such compartments is crucial. Thus, we examined whether the $\mathrm{CB}$ [7]-based ultrastable binding pair could 'latch' $\mathrm{Cy} 3-\mathrm{CB}[7]$ to AdA-labeled proteins in specific cellular organelles, thereby visualizing proteins in these compartments. To achieve this, we used two different proximitydependent protein adamantylation approaches: (1) an immunospecifically introduced peroxidase (HRP) for fixed cells (Fig. 5); and (2) an engineered APEX2 for living cells (Fig. 6) ${ }^{34}$. For proximity-dependent adamantylation of proteins in fixed cells, we used a similar strategy as in the previous section. In this case, we immunospecifically introduced HRP to the nucleus of COS7 cells by expressing FLAG $^{\oplus}$-tagged histone H3 protein (FLAG-H3). Before performing HRP-induced adamantylation, we first confirmed the successful expression of FLAG-H3 in the nucleus of the cells by observing well-overlapped fluorescence signal of DAPI (a staining dye for the cell nucleus) with that of immunospecifically labeled Alexa 555-conjugated secondary antibody, which specifically recognizes anti-FLAG primary antibody (Supplementary Figure 8). The COS7 cells were fixed and sequentially treated with anti-FLAG primary antibody, HRP-conjugated secondary antibody, and AdA-phenol with $\mathrm{H}_{2} \mathrm{O}_{2}$ by following the same procedure as we performed for the visualization of cytoplasmic proteins with FLAG-eGFP. After the cells were treated with DAPI and Cy3-CB[7], fluorescence microscopy was used to examine the location of the AdA-labeled proteins. The signal from Cy3-CB[7] was well-overlapped with that of DAPI (Fig. 5), suggesting that the proteins were labeled exclusively in the nucleus and $\mathrm{Cy} 3-\mathrm{CB}[7]$ latches onto those labeled proteins selectively. In summary, the combination of proximity-based labeling and an ultrastable host-guest interaction between Cy3$\mathrm{CB}[7]$ and AdA allows visualization of the proteins in compartments deep inside fixed cells.

Organelle-specific protein labeling in living cells can be achieved by using an engineered APEX2. Although APEX2 and HRP seem to work similarly in terms of reaction chemistry, HPR does not have sufficient reactivity in living cells, but APEX2 does $^{34}$. We investigated whether APEX2 could be used to label proximal proteins with AdA and then see if Cy3-CB[7] could visualize those proteins. We ectopically expressed the mito-V5APEX2 fusion protein which was designed to translocate into the mitochondrial matrix in COS7 cells. The V5 epitope (a polypeptide protein tag-GKPIPNPLLGLDST) allowed visualization of the protein using anti-V5 antibody for immunospecific fluorescence labeling ${ }^{35}$. Protein labeling inside the organelle of the living cells was initiated by treatment with AdA-phenol (for $30 \mathrm{~min})$ and $\mathrm{H}_{2} \mathrm{O}_{2}(1.0 \mathrm{mM}$ for $2 \mathrm{~min}$, which is endurable for living cells $)^{34}$. Immediately after quenching the remaining radicals with sodium azide and sodium ascorbate, the cells were fixed and treated with $\mathrm{Cy} 3-\mathrm{CB}[7]$ to visualize the AdA-labeled proteins in the cells. In parallel, we performed immunofluorescence labeling with anti-V5 primary antibody and Alexa647conjugated secondary antibody to confirm the subcellular localization of mito-V5-APEX2 enzyme in the cells. Using confocal laser scanning microscopy, we observed the fluorescence 


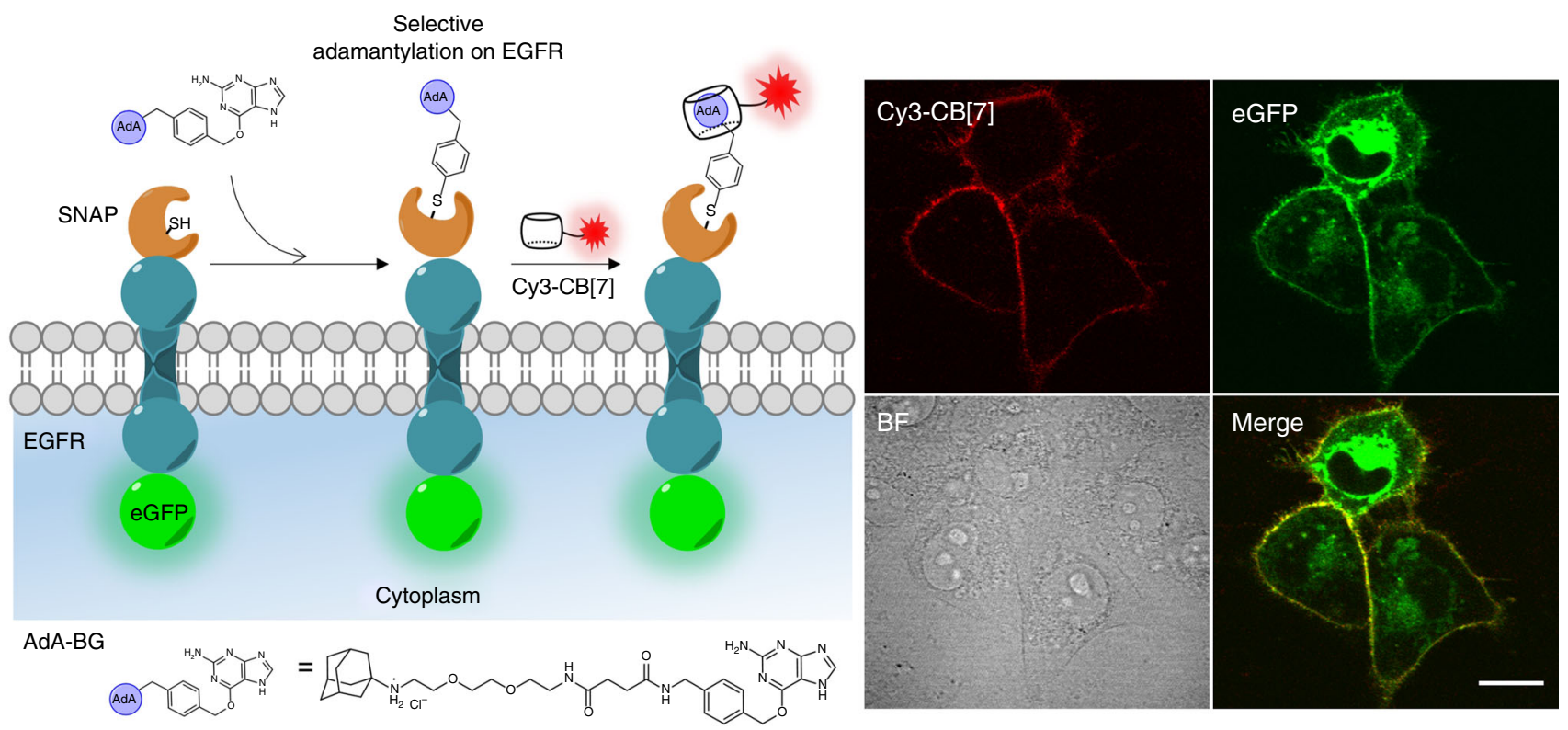

Fig. 7 Visualization of a target specific protein. Schematic illustration of adamantylation on r-EGFR using SNAP-tag method. Confocal laser scanning microscopy images of COS7 cells which have SNAP and eGFP-tagged recombinant EGFR expressed in the plasma membrane. Scale bar $=20 \mu \mathrm{m}$

signal corresponding to the immunospecific labeling of the V5epitope (Fig. 6). The signal appeared as a punctuated structure which is a characteristic structural feature of mitochondria, suggesting that mito-V5-APEX2 is well expressed and located in the target organelle. We also observed the signal corresponding to Cy3-CB[7] and found that the signal was well-overlapped with that of immunofluorescence signal of V5 (Fig. 6). These results showed that spatially restricted adamantylation of the proteins in a specific subcellular organelle in living cells can be performed using mito-V5-APEX enzyme and the adamantylated proteins can be specifically visualized with $\mathrm{Cy} 3-\mathrm{CB}[7]$ via the ultrastable host-guest interactions between $\mathrm{CB}[7]$ and AdA. In addition, we found that the cells required at least $25 \mu \mathrm{M}$ of AdA-phenol treatment for efficient enzyme-assisted proximity-dependent protein adamantylation to visualize the target proteins with Cy3-CB[7]; however, $250 \mu \mathrm{M}$ of AdA-phenol seemed to be optimum for the conditions that we tested in this study.

Visualization of target-specific proteins. To understand the roles of specific proteins involved in cellular functions, visualization of specific proteins in living cells is of a great interest in chemical biology $^{36-39}$. For this purpose, we investigated whether the supramolecular latching system could be exploited for the imaging of specific target proteins in living cells (Fig. 7). SNAPtag is a mutant of the DNA-repair protein, $\mathrm{O}^{6}$-alkylguanine-DNA alkyltransferase, and can be ectopically expressed as a fusion protein with the target protein. SNAP-tag reacts spontaneously with benzylguanine (BG) derivatives to make a covalent conjugation of $\mathrm{BG}$ derivative to the SNAP-tag-fusion protein. Into living cells, we transfected a DNA construct encoding a plasma membrane receptor that contains an $\mathrm{N}$-terminal SNAP and $\mathrm{C}$ terminal eGFP-tagged EGFR (SNAP and eGFP recombinant EGFR, r-EGFR). After transfection, the cells were incubated with a SNAP-reactive AdA molecule, AdA-BG (Supplementary Figure 4), and then treated with $\mathrm{Cy} 3-\mathrm{CB}[7]$. Confocal laser scanning microscopy revealed that the fluorescence signals from $\mathrm{Cy} 3-\mathrm{CB}$ [7] mainly arose from the surface of the cells, which is welloverlapped with that from eGFP. (Fig. 7) This result suggested that the cell surface-exposed SNAP-tag on r-EGFR was specifically adamantylated with AdA-BG and Cy3-CB[7] was
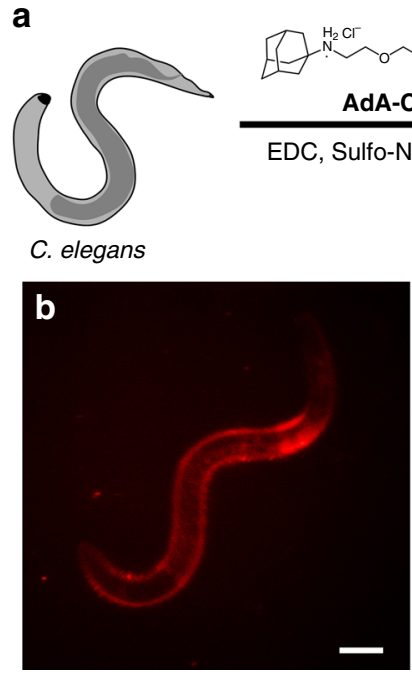

Fig. 8 Visualization of a simple animal model (C. elegans). a Schematic illustration of adamantylation on $C$. elegans and $\mathbf{b}$ fluorescence microscopy images of $C$. elegans after treating with $C y 3-C B[7]$. Scale bar $=50 \mu \mathrm{m}$

successfully latched to the adamantylated protein through the ultrastable host-guest chemistry.

Visualization of proteins on a living animal (C. elegans). Not limited to cell-level imaging, we investigated whether the supramolecular latching system can be extended to animal-level imaging. As a simple animal model, we choose C. elegans, which is a nematode (roundworm) about $1 \mathrm{~mm}$ in length when it becomes an adult. Owing to easy cultivation, well-known anatomical information, and transparency, C. elegans have been widely used for fluorescence bioimaging studies of multicellular organisms. After treating C. elegans with AdA-COOH (see Supplementary Figure 4), activated with $N$-hydroxysulfosuccinimide sodium salt (sulfo-NHS) and EDC, we then treated with Cy3-CB[7] and imaged it under a fluorescence microscope. The fluorescence signal from Cy3-CB[7] appeared mostly on the surface of 
C. elegans (Fig. 8), whereas almost no fluorescence was observed from C. elegans that was not treated with AdA-COOH (Supplementary Figure 9). These results indicated that AdA-COOH seemed to be conjugated to the proteins mostly on the surface of C. elegans and $\mathrm{Cy} 3-\mathrm{CB}[7]$ efficiently latched onto the proteins to be visualized. Taken together, $\mathrm{CB}[7]$-based ultrastable binding pairs are potentially useful as a supramolecular latching system even for animal-level imaging.

\section{Discussion}

We have demonstrated that small, non-protein-based synthetic binding pairs can act as a switchable supramolecular latching system for the fluorescence imaging of proteins located in and on fixed or living cells. These pairs are not only a replacement of SA-BT, they are superior on account of their bioorthogonality in binding, controllability of their binding, chemical stability, and small size. Proteins in (or on) the cells were adamantylated (or ferrocenylated) using various labeling approaches such as direct chemical labeling through EDC coupling, enzyme-assisted labeling with immunospecifically introduced peroxidase (HRP), genetically expressed peroxidase (APEX2), and a self-labeling protein (SNAP-tag). Cy3-CB[7] can be latched to the adamantylated (or ferrocenylated) proteins by taking advantage of the ultrastable host-guest interaction between $\mathrm{Cy3}-\mathrm{CB}[7]$ and AdA (or FcA). Successful visualization of the proteins with cells and $C$. elegans suggests that the supramolecular latching system has great potential for various living organism bioimaging, from cells to animals. We observed exceptional selectivity of $\mathrm{CB}$ [7] to AdA (or FcA) with no interference from endogenous biomolecules enabling us to have clear fluorescence images for accurate and precise analysis of protein locations using fluorescence microscopy. This is in contrast to SA-BT, which can be subject to interference from endogenous biotin and biotinylated proteins. Conditional unlatching of $\mathrm{Cy} 3-\mathrm{CB}[7]$ from FcA (or AdA)-labeled proteins on living cells membrane by guest exchange allowed us to selectively visualize intracellularly translocated proteins. Moreover, no significant non-specific adsorption of Cy3-CB[7] onto the cells or C. elegans was observed. The concentration range of Cy3-CB[7] (between $25 \mathrm{nM}$ and $100 \mathrm{nM}$ ) used in the cell and C. elegans experiments seems to be the optimal range for the reagent. When the concentration of $\mathrm{Cy} 3-\mathrm{CB}[7]$ is less than 25 $\mathrm{nM}$, visualization of proteins in cells and animals is difficult to achieve. On the other hand, when more than $100 \mathrm{nM}$ is used, the background signal can be high, especially in the case of fixed cells. These results can serve as starting points in the optimization of treatment conditions for other protein imaging assays with cells and animals. Taken together, the $\mathrm{CB}$ [7]-based system reported here demonstrates the great potential of the ultrastable synthetic binding pairs as a new tool for cell and animal-level bioimaging. The small size of these pairs (relative to proteins) and their ability to selectively label proteins of interest with FcA (or AdA), using chemical or genetic approaches, may allow for super-resolution imaging of proteins and their dynamic behaviors such as vesicle trafficking; work along this line is currently underway.

\section{Methods}

Transfection of genes to the cells. COS7 cells were cultured in DMEM supplemented with $10 \%(\mathrm{v} / \mathrm{v})$ fetal bovine serum at $37^{\circ} \mathrm{C}$ in a humidified $\mathrm{CO}_{2}$-controlled (5\%) incubator. For transfection and transient expression of proteins, the cells were transfected with plasmids encoding a recombinant gene using Lipofectamine $^{\mathrm{TM}} 2000$ (Invitrogen, Carlsbad, CA). According to the manufacturer's instructions, transfections were performed and the cells were then cultured for an additional $24 \mathrm{~h}$ to achieve ectopic expression of interest proteins.

Visualization of AdA-labeled proteins with Cy3-CB[7]. The COS7 cells cultured on a circular cover glass (16 mm in diameter) were cultured in DMEM (1.0 ml) supplemented with $10 \%$ fetal bovine serum at $37^{\circ} \mathrm{C}$ under $5 \% \mathrm{CO}_{2}$. The cells were fixed with $4 \%$ formaldehyde in phosphate-buffered saline (PBS) $(1.0 \mathrm{ml})$ at room temperature for $15 \mathrm{~min}$ and washed with PBS $(5 \times, 1.0 \mathrm{ml})$ and permeabilized with a solution of $0.5 \%$ Triton X-100 in PBS $(1.0 \mathrm{ml})$ for $5 \mathrm{~min}$ at room temperature. The cells were washed again $(3 \times)$ with PBS $(1.0 \mathrm{ml})$ at room temperature and treated with a solution of $3 \%$ bovine serum albumin (BSA) in Tris-buffered saline with $0.1 \%$ of Tween 20 (TBST) $(1.0 \mathrm{ml})$. The cells were stained with anti-golgin97 primary antibody (Invitrogen, 1:1000) in the blocking buffer for $1 \mathrm{~h}$ at room temperature and washed with PBS $(5 \times, 1.0 \mathrm{ml})$.

Golgin97 imaging using AdA-secondary antibody: The AdA-conjugated secondary goat anti-mouse antibody (1:300), Cy3-CB[7] $(25 \mathrm{nM})$, and secondary anti-mouse-AF647 antibody (Invitrogen 1:1000) were mixed in PBS $(50 \mu \mathrm{l})$. The mixture was purified by centrifugal filtration (MWCO, $30 \mathrm{kDa}$ ) with PBS to obtain the antibody mixture solution. After mixing with a blocking buffer $(450 \mu \mathrm{l})$, the solution was introduced to the cells to stain the golgin 97 for confocal laser scanning microscopy.

Golgi97 imaging using BT-secondary antibody: The BT-conjugated secondary goat anti-mouse antibody (Invitrogen, 1:8000) and secondary anti-mouse-AF555 antibody (Invitrogen, 1:1000) were mixed in blocking buffer. The cells were stained with the mixture for $1 \mathrm{~h}$ at room temperature. After washing $(5 \times, 1.0 \mathrm{ml})$ with a solution of TBST, the cells were stained with AF647-SA (Invitrogen, 1:1000) for $1 \mathrm{~h}$ at room temperature for confocal laser scanning microscopy. The cells on the cover glass were examined by a confocal laser scanning microscope system (LSM 700, Zeiss) with $63 \times / 1.40$ NA Oil objective.

The confocal laser scanning microscopy images (Fig. 2a-h) were used for calculation of colocalization efficiency (\%) between AF647-SA and AF555secondary antibody, and $\mathrm{Cy} 3-\mathrm{CB}[7]$ and AF647-secondary antibody. The numbers $(\#)$ of the fluorescently stained pixels and their overlapping were obtained from a imaging software (ZEN, Zeiss). The fluorescence signals of AF555- and AF647secondary antibodies were almost included in those of AF647-SA and Cy3-CB[7], respectively (Supplementary Figure 5). The values for the colocalization efficiency (see Supplementary Table 2 ) were calculated by $\left(N_{\mathrm{Ov1}} / N_{\mathrm{AF} 647-\mathrm{SA}}\right) \times 100$ and $\left(N_{\mathrm{Ov} 2 /} N_{\mathrm{Cy} 3-\mathrm{CB}[7]}\right) \times 100$ with five different cells for target protein imaging with AF647-SA and Cy3-CB[7], respectively. The closer the values were to $100 \%$, the more precise and accurate imaging of the target protein (Golgi 97). $N_{\text {Ov1 }}$

\# of pixels overlapping between AF647-SA and AF555-secondary antibody =

\# of pixels stained with AF647-SA for BT-secondary antibody $=N_{\mathrm{AF} 647-\mathrm{SA}}$ $N_{\text {Ov2 }}$

\# of pixels overlapping between $\mathrm{Cy} 3-\mathrm{CB}[7]$ and AF647-secondary antibody =

\# of pixels stained with Cy3-CB[7] for AdA-secondary antibody $=N_{\mathrm{Cy3}-\mathrm{CB}[7]}$

Visualization of FcA-labeled proteins. COS7 cells were cultured on a circular cover glass ( $16 \mathrm{~mm}$ in diameter) in a 24 -well plate to $70-80 \%$ confluency and briefly washed with ice-cold PBS three times before the treatment of labeling reagents. The cells in the culture medium $(1.0 \mathrm{ml})$ were treated with (or without) a solution of FcA-COOH $(0.4 \mathrm{mg})^{25}$, sulfo-NHS $(0.3 \mathrm{mg})$, and EDC $(0.3 \mathrm{mg})$ in PBS $(10 \mu \mathrm{l})$, and then incubated for $30 \mathrm{~min}$ at $4{ }^{\circ} \mathrm{C}$, followed by washing with ice-cold PBS three times. The cells were additionally incubated in a solution of $\mathrm{Cy} 3-\mathrm{CB}[7]$ $(100 \mathrm{nM})$ in PBS $(1.0 \mathrm{ml})$ for $10 \mathrm{~min}$ at $4{ }^{\circ} \mathrm{C}$ and washed with PBS $(1.0 \mathrm{ml})$ three times. The cells applied with a drop of VECTASHIELD ${ }^{\oplus}$ (an antifade mounting medium with DAPI) on the cover glass were examined by a confocal laser scanning microscope system (LSM 700, Zeiss) with $63 \times / 1.40$ NA Oil objective.

Supramolecular latch-off of Cy3-CB[7] from the FcA protein. The cells with $\mathrm{Cy} 3-\mathrm{CB}[7]$ latched to the plasma membrane proteins, prepared as above, were incubated with BAFc $(2 \mu \mathrm{l}, 10 \mathrm{mM})$ for $20 \mathrm{~min}$ in the culture medium $(200 \mu \mathrm{l})$ at $4{ }^{\circ}$ C. After washing the cells with PBS $(1.0 \mathrm{ml})$ three times, the cells applied with a drop of VECTASHIELD on the cover glass were examined by confocal laser scanning microscope system (LSM 700, Zeiss) with $63 \times / 1.40$ NA Oil objective.

Visualization of intracellularly translocated proteins. The COS7 cells with Cy3$\mathrm{CB}$ [7] on the surface, prepared as above, were further incubated at $37^{\circ} \mathrm{C}$ for $2 \mathrm{~h}$ and washed with PBS $(1.0 \mathrm{ml})$ three times. The washed cells were treated with BAFc and further incubated for $20 \mathrm{~min}$ at $4{ }^{\circ} \mathrm{C}$. The cells were washed with PBS $(1.0 \mathrm{ml})$ three times and applied with a drop of VECTASHIELD ${ }^{\circ}$ on the cover glass were examined by confocal laser scanning microscope system (LSM 700, Zeiss) with $63 \times / 1.40$ NA Oil objective.

Immunofluorescence labeling. The COS7 cells cultured on a circular cover glass (16 $\mathrm{mm}$ in diameter) treated with samples were fixed in a solution of paraformaldehyde $(4 \%)$ in PBS $(1.0 \mathrm{ml})$ at room temperature for $15 \mathrm{~min}$. Then, the cells were washed three times with PBS and permeabilized with a solution of Triton X$100(0.5 \%)$ in PBS $(1.0 \mathrm{ml})$ for $15 \mathrm{~min}$. After incubation with a solution of BSA (3\%) in PBS $(1.0 \mathrm{ml})$ as a blocking buffer for $15 \mathrm{~min}$, the cells were stained with anti-FLAG (Sigma-Aldrich, 1:1000 dilution) or anti-V5 mouse antibodies (Invitrogen; 1:1000 dilution) in the blocking buffer $(1.0 \mathrm{ml})$ overnight, and then washed five times with a solution of Tween-20 $(0.1 \%)$ in PBS (PBST) $(1.0 \mathrm{ml})$. After this, the cells were either processed for immunofluorescence or for immunospecifically proximate protein labeling. For immunofluorescence imaging, the cells were 
incubated with a solution of Alexa488-conjugated anti-mouse IgG secondary antibody (Invitrogen; 1:1000 dilution) in the blocking buffer $(1.0 \mathrm{ml})$ for $1 \mathrm{~h}$ at room temperature. After five washings with PBST, the cells were examined under an epi-fluorescence microscope as previously described for the imaging of the cell surface proteins.

For immunospecifically proximity-dependent protein labeling, the cells were incubated with a solution of HRP-conjugated anti-mouse IgG secondary antibody (Cell Signaling Technology; 1:1000 dilution) in the blocking buffer (1.0 ml) for $3 \mathrm{~h}$ at room temperature. After five washings with PBST $(1.0 \mathrm{ml})$, the cells were treated with AdA-phenol $(250 \mu \mathrm{M}), \mathrm{H}_{2} \mathrm{O}_{2}(1 \mathrm{mM})$ in PBS $(1.0 \mathrm{ml})$ for $2 \mathrm{~min}$. Thereafter, the reaction was quenched with a solution of sodium azide $(10 \mathrm{mM})$ and sodium ascorbate $(10 \mathrm{mM})$ in PBS $(2 \mathrm{ml})$. The cells were incubated in the blocking buffer $(1.0 \mathrm{ml})$ for $15 \mathrm{~min}$ and then treated with $\mathrm{Cy3}-\mathrm{CB}$ [7] $(100 \mathrm{nM})$ prepared in the blocking buffer $(1.0 \mathrm{ml})$ for $30 \mathrm{~min}$ at room temperature. After five washings with PBST $(1.0 \mathrm{ml})$, the cells were examined under an epi-fluorescence microscope as previously described for the imaging of cell surface proteins.

APEX2-dependent protein labeling and imaging. After the transfection of mitoV5-APEX2 to COS7 cells on a circular cover glass (16 $\mathrm{mm}$ in diameter), the cells were treated with AdA-phenol $(250 \mu \mathrm{M})$ in a cell culture medium $(1.0 \mathrm{ml})$ and incubated for $30 \mathrm{~min}$ at $37^{\circ} \mathrm{C}$, then treated with $\mathrm{H}_{2} \mathrm{O}_{2}(1.0 \mathrm{ml}, 1 \mathrm{mM})$ for $2 \mathrm{~min}$ to initiate adamantylation. The reaction was quenched with a solution of sodium azide $(5 \mathrm{mM})$ and sodium ascorbate $(5 \mathrm{mM})$ in PBS $(2.0 \mathrm{ml})$. Thereafter, the cells were fixed in a solution of paraformaldehyde $(4 \%)$ in PBS $(1.0 \mathrm{ml})$ at room temperature for $15 \mathrm{~min}$. The fixed cells were washed three times with PBS $(1.0 \mathrm{ml})$ and permeabilized with a solution of Triton X-100 (0.5\%) in PBS $(1.0 \mathrm{ml})$ for $15 \mathrm{~min}$. After incubation with the blocking buffer $(2.0 \mathrm{ml})$ for $15 \mathrm{~min}$, the cells were incubated with a solution of anti-V5 primary antibody (Invitrogen; 1:1000 dilution) in the blocking buffer solution $(1.0 \mathrm{ml})$ for $8 \mathrm{~h}$ and then washed five times with PBS $(1.0 \mathrm{ml})$. The washed cells were incubated with a solution of Cy3-CB[7] $(50 \mathrm{nM})$ and Alexa647-conjugated anti-mouse IgG secondary antibody (Invitrogen; 1:1000 dilution) in the blocking buffer $(1.0 \mathrm{ml})$ for $1 \mathrm{~h}$ at room temperature. After further five washings with PBS $(1.0 \mathrm{ml})$, the cells on the cover glass were examined under a confocal laser scanning microscope (FV1000, Olympus) with $60 \times / 1.42$ Oil objective.

SNAP-based specific protein labeling and imaging. After the transfection of $\mathrm{N}$ terminal SNAP and C-terminal eGFP-tagged EGFR, the cells on a cover glass ( $16 \mathrm{~mm}$ in diameter) were treated with a solution of AdA-BG $(10 \mu \mathrm{M})$ in a serum-free cell culture medium $(1.0 \mathrm{ml})$ and incubated for $30 \mathrm{~min}$ at $37^{\circ} \mathrm{C}$. Then, the cells were washed with PBS three times and treated with a solution of Cy3-CB[7] $(200 \mathrm{nM})$ in a blocking buffer $(1.0 \mathrm{ml})$ for another $30 \mathrm{~min}$ at room temperature. After five times washings with PBS, the cells on a cover glass were examined under confocal laser scanning microscope (FV1000, Olympus) with $60 \times / 1.42 \mathrm{NA}$ Oil objective.

Protein labeling and imaging on C. elegans. C. elegans (wild-type $\mathrm{N}_{2}$ ) was provided by Caenorhabditis Genetics Center (CGC), University of Minnesota, and maintained as required. Briefly, C. elegans was cultured on solid Nematode Growth Medium (NGM) plates and fed with a lawn of OP50 (a uracil auxotrophic Escherichia coli strain which grows slowly on NGM plates) at room temperature. For all experiments, the eggs of C. elegans were isolated in advance and collected in M9 buffer, and then L1 stage larvae are hatched after incubation at room temperature for $24 \mathrm{~h}$. After ca. 100 newly hatched L1 larvae were briefly washed with M9 buffer $(1.0 \mathrm{ml})$ three times, the larvae were treated with a solution $(50 \mu \mathrm{l})$ of AdA-COOH (1.0 mg), sulfo-NHS $(0.7 \mathrm{mg})$, and EDC $(0.7 \mathrm{mg})$ in M9 buffer $(1.0$ $\mathrm{ml}$ ) and incubated for $4 \mathrm{~h}$ at $4{ }^{\circ} \mathrm{C}$. After washing with an ice-cold M9 buffer, the larvae were incubated in a solution of Cy3-CB[7] $(100 \mathrm{nM})$ in $\mathrm{M} 9$ buffer $(50 \mu \mathrm{l})$ for $10 \mathrm{~min}$ at room temperature. After another washing step with ice-cold M9 buffer, the C. elegans were placed on an agar-coated slide glass and examined under an epi-fluorescence microscope (Eclipse Ti-E, Nikon) with $20 \times / 0.75$ NA objective.

Data availability. The authors declare that the main data supporting the findings of this study are available within the article and its Supplementary Information files. Extra data are available from the corresponding author upon request.

Received: 9 March 2017 Accepted: 2 April 2018

Published online: 27 April 2018

\section{References}

1. Swamy, M. J. Thermodynamic analysis of biotin binding to avidin. A high sensitivity titration calorimetric study. Biochem. Mol. Biol. Int. 36, 219-225 (1995).

2. Howarth, M. \& Ting, A. Y. Imaging proteins in live mammalian cells with biotin ligase and monovalent streptavidin. Nat. Protoc. 3, 534-545 (2008).
3. Reimann, O., Smet-Nocca, C. \& Hackenberger, C. P. R. Traceless purification and desulfurization of tau protein ligation products. Angew. Chem. Int. Ed. 54, 306-310 (2015)

4. Sreekanth, K. V. et al. Extreme sensitivity biosensing platform based on hyperbolic metamaterials. Nat. Mater. 15, 621-627 (2016).

5. Berntzen, G. et al. Characterization of an Fc gamma RI-binding peptide selected by phage display. Protein Eng. Des. Sel. 19, 121-128 (2006).

6. Jungmann, R. et al. Multiplexed 3D cellular super-resolution imaging with DNA-PAINT and Exchange-PAINT. Nat. Methods 11, 313-318 (2014).

7. Bussolati, G., Gugliotta, P., Volante, M., Pace, M. \& Papotti, M. Retrieved endogenous biotin: a novel marker and a potential pitfall in diagnostic immunohistochemistry. Histopathology 31, 400-407 (1997).

8. Rusckowski, M., Fogarasi, M., Fritz, B. \& Hnatowich, D. J. Effect of endogenous biotin on the applications of streptavidin and biotin in mice. Nucl. Med. Biol. 24, 263-268 (1997).

9. Banks, R. E., Craven, R. A., Harnden, P. A. \& Selby, P. J. Use of a sensitive EnVision (TM)+-based detection system for Western blotting: avoidance of streptavidin binding to endogenous biotin and biotin-containing proteins in kidney and other tissues. Proteomics 3, 558-561 (2003).

10. Tytgat, H. L. P. et al. Endogenous biotin-binding proteins: an overlooked factor causing false positives in streptavidin-based protein detection. Microb. Biotechnol. 8, 164-168 (2015).

11. Horling, L., Neuhuber, W. L. \& Raab, M. Pitfalls using tyramide signal amplification (TSA) in the mouse gastrointestinal tract: endogenous streptavidin-binding sites lead to false positive staining. J. Neurosci. Methods 204, 124-132 (2012).

12. Lee, J. W., Samal, S., Selvapalam, N., Kim, H. -J. \& Kim, K. Cucurbituril homologues and derivatives: new opportunities in supramolecular chemistry. Acc. Chem. Res. 36, 621-630 (2003).

13. Barrow, S. J., Kasera, S., Rowland, M. J., del Barrio, J. \& Scherman, O. A. Cucurbituril-based molecular recognition. Chem. Rev. 115, 12320-12406 (2015).

14. Jeon, W. S. et al. Complexation of ferrocene derivatives by the cucurbit[7]uril host: a comparative study of the cucurbituril and cyclodextrin host families. $J$. Am. Chem. Soc. 127, 12984-12989 (2005).

15. Liu, S. M. et al. The cucurbit[n] uril family: prime components for self-sorting systems. J. Am. Chem. Soc. 127, 15959-15967 (2005).

16. Rekharsky, M. V. et al. A synthetic host-guest system achieves avidin-biotin affinity by overcoming enthalpy-entropy compensation. Proc. Natl Acad. Sci. USA 104, 20737-20742 (2007).

17. Moghaddam, S. et al. New ultrahigh affinity host-guest complexes of cucurbi [7] uril with bicyclo[2.2.2] octane and adamantane guests: thermodynamic analysis and evaluation of M2 affinity calculations. J. Am. Chem. Soc. 133, 3570-3581 (2011).

18. Cao, L. P. et al. Cucurbit[7] uril.guest pair with an attomolar dissociation constant. Angew. Chem. Int. Ed. 53, 988-993 (2014).

19. Isaacs, L. Stimuli responsive systems constructed using cucurbit[n]uril-type molecular containers. Acc. Chem. Res. 47, 2052-2062 (2014).

20. Assaf, K. I. \& Nau, W. M. Cucurbiturils: from synthesis to high-affinity binding and catalysis. Chem. Soc. Rev. 44, 394-418 (2015).

21. Shetty, D., Khedkar, J. K., Park, K. M. \& Kim, K. Can we beat the biotin-avidin pair?: cucurbit[7]uril-based ultrahigh affinity host-guest complexes and their applications. Chem. Soc. Rev. 44, 8747-8761 (2015)

22. Park, K. M., Murray, J. \& Kim, K. Ultrastable artificial binding pairs as a supramolecular latching system: a next generation chemical tool for proteomics. Acc. Chem. Res. 50, 644-646 (2017).

23. Lee, D. W. et al. A simple modular aptasensor platform utilizing cucurbit[7] uril and a ferrocene derivative as an ultrastable supramolecular linker. Chem. Commun. 51, 3098-3101 (2015).

24. Ahn, Y., Jang, Y., Selvapalam, N., Yun, G. \& Kim, K. Supramolecular velcro for reversible underwater adhesion. Angew. Chem. Int. Ed. 52, 3140-3144 (2013).

25. Lee, D. W. et al. Supramolecular fishing for plasma membrane proteins using an ultrastable synthetic host-guest binding pair. Nat. Chem. 3, 154-159 (2011).

26. Tonga, G. Y. et al. Supramolecular regulation of bioorthogonal catalysis in cells using nanoparticle-embedded transition metal catalysts. Nat. Chem. 7, 597-603 (2015).

27. Kim, C., Agasti, S. S., Zhu, Z. J., Isaacs, L. \& Rotello, V. M. Recognitionmediated activation of therapeutic gold nanoparticles inside living cells. Nat. Chem. 2, 962-966 (2010).

28. Gong, B. et al. High affinity host-guest FRET pair for single-vesicle contentmixing assay: observation of flickering fusion events. J. Am. Chem. Soc. 137, 8908-8911 (2015)

29. Bockus, A. T. et al. Cucurbit[7] uril-tetramethylrhodamine conjugate for direct sensing and cellular imaging. J. Am. Chem. Soc. 138, 16549-16552 (2016). 
30. Li, M. et al. Autophagy caught in the act: a supramolecular FRET pair based on an ultrastable synthetic host-guest complex visualizes autophagosomelysosome fusion. Angew. Chem. Int. Ed. 57, 2120-2125 (2018).

31. Einhauer, A. \& Jungbauer, A. The FLAG peptide, a versatile fusion tag for the purification of recombinant proteins. J. Biochem. Biophys. Methods 49, 455-465 (2001).

32. Minamihata, K., Goto, M. \& Kamiya, N. Site-specific protein cross-linking by peroxidase-catalyzed activation of a tyrosine-containing peptide tag. Bioconjug. Chem. 22, 74-81 (2011).

33. Lowe, M. \& Barr, F. A. Inheritance and biogenesis of organelles in the secretory pathway. Nat. Rev. Mol. Cell Biol. 8, 429-439 (2007).

34. Rhee, $\mathrm{H}$. W. et al. Proteomic mapping of mitochondria in living cells via spatially restricted enzymatic tagging. Science 339, 1328-1331 (2013).

35. Casper, J. M. et al. The c-myc DNA-unwinding element-binding protein modulates the assembly of DNA replication complexes in vitro. J. Biol. Chem. 280, 13071-13083 (2005).

36. Xue, L., Karpenko, I. A., Hiblot, J. \& Johnsson, K. Imaging and manipulating proteins in live cells through covalent labeling. Nat. Chem. Biol. 11, 917-923 (2015).

37. Pratt, C. P., He, J. J., Wang, Y., Barth, A. L. \& Bruchez, M. P. Fluorogenic green-inside red-outside (GIRO) labeling approach reveals adenylyl cyclasedependent control of BK alpha surface expression. Bioconjug. Chem. 26, 1963-1971 (2015).

38. Li, C. G. et al. Dynamic multicolor protein labeling in living cells. Chem. Sci. 8, 5598-5605 (2017).

39. Fisher, G. W. et al. Self-checking cell-based assays for GPCR desensitization and resensitization. J. Biomol. Screen. 19, 1220-1226 (2014).

\section{Acknowledgements}

This work was supported by the Institute for Basic Science (IBS) [IBS-R007-D1]. A.L. acknowledges a National Research Foundation of Korea (NRF) grant funded by the Korean Government (NRF-2017H1A2A1044903-Global Ph.D. Fellowship Program). We thank Prof. Jin Il Lee (Yonsei University) and Prof. Hyun-Woo Rhee (UNIST) for providing us with E. coli (OP50) for C. elegans cultivation and a plasmid for expression of mito-V5-APEX.

\section{Author contributions}

K.L.K. and K.M.P. conceived the idea. K.L.K., J.M., K.M.P., and K.K. wrote the manuscript. K.L.K., G.S., J.S., J.M., and K.M.P. performed the cell experiments. M.L., A.L., and K.M.P. performed animal experiments. K.L.K., G.S., A.S., and K.M.P. synthesized the materials. All authors discussed the results and approved the final version of the manuscript.

\section{Additional information}

Supplementary Information accompanies this paper at https://doi.org/10.1038/s41467018-04161-4.

Competing interests: The authors declare no competing interests.

Reprints and permission information is available online at http://npg.nature.com/ reprintsandpermissions/

Publisher's note: Springer Nature remains neutral with regard to jurisdictional claims in published maps and institutional affiliations.

(c) (i) Open Access This article is licensed under a Creative Commons Attribution 4.0 International License, which permits use, sharing, adaptation, distribution and reproduction in any medium or format, as long as you give appropriate credit to the original author(s) and the source, provide a link to the Creative Commons license, and indicate if changes were made. The images or other third party material in this article are included in the article's Creative Commons license, unless indicated otherwise in a credit line to the material. If material is not included in the article's Creative Commons license and your intended use is not permitted by statutory regulation or exceeds the permitted use, you will need to obtain permission directly from the copyright holder. To view a copy of this license, visit http://creativecommons.org/ licenses/by/4.0/.

(C) The Author(s) 2018 